\title{
Lesbian Leaves
}

\author{
Janice Andreae
}

Lesbian leaf, a variation of a water leaf, is a type of classical ornament, often found on a lesbian cyma or cyma reversa moulding, derived from and resembling the leaves of plants; for example, the water lily, the lotus leaf, or ivy leaves. (In this case, the leaf is an oak leaf, which is not surprising since the building with this architectural language is located on Bay Street, south of Toronto's Old City Hall on Queen Street, the heart of Canada's economic trade and commerce). A lesbian cyma or cyma reversa moulding is a projecting moulding common in classical architecture usually forming part of the entablature or frieze of a building or used as the crowning moulding of a classical cornice, named by Vitruvius as the cymatium. The form of the lesbian cyma is a double curvature that is convex at the outer edge and concave at the inner edge in contrast with the cyma recta (also known as the Doric cyma) that is concave at the outer edge and convex at the inner edge.

The image of the sequential frames of two women dancing is appropriated from an 1887 portfolio of the Victorian British photographer Eadweard Muybridge. Two women dancing a waltz is one of his photographic sequence studies of the human figure in motion published in the Prospectus and Catalogue of Plates in his text Animal Locomotion, 1887. 
Lesbian Leaves · 33

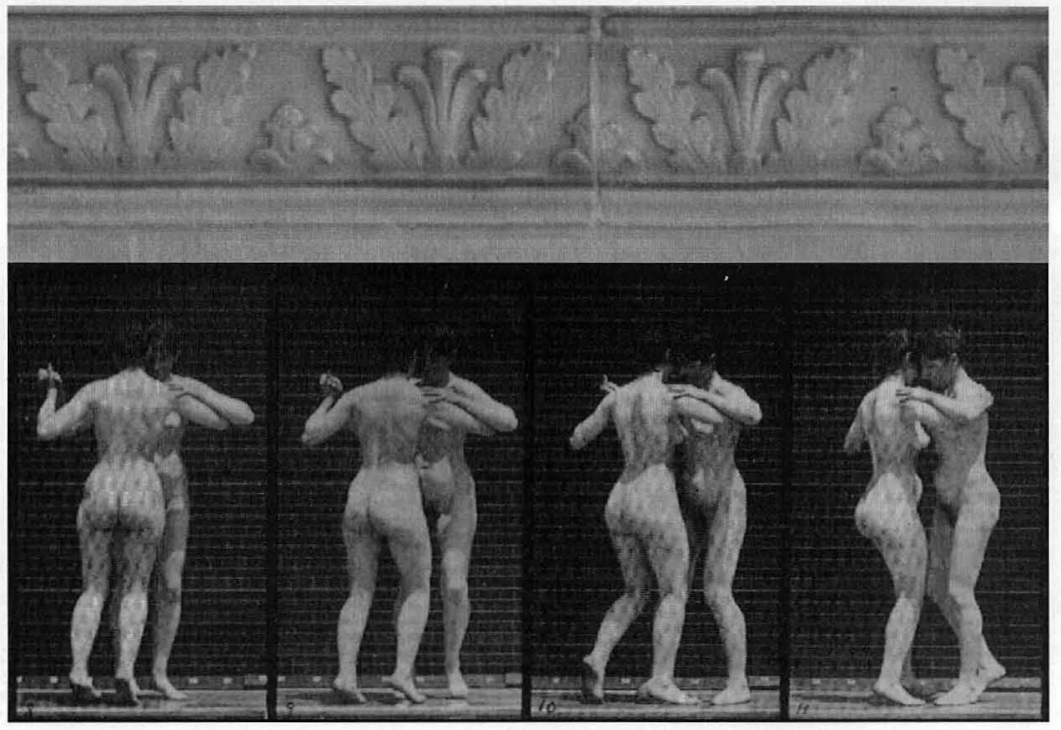

